\title{
Management of cracked tooth using simvastatin as intra-canal medicament
}

\author{
Hatem Alhadainy ${ }^{1}$, Mohamed Fawzy ${ }^{2}$, Muhammad Salah-Uddin², and Saleem Abdulrab ${ }^{3}$ \\ ${ }^{1}$ Tanta University Faculty of Dentistry \\ ${ }^{2}$ Tanta University \\ ${ }^{3}$ Primary Health Care Corporation
}

June 12,2020

\begin{abstract}
Cracked tooth syndrome is a common well documented condition that many occur due to morphologic, physical and iatrogenic factors. Epidemiologic data revealed that splits or fractures are the third most common cause of tooth loss. Simvastatin allowed a good management for a case suffered from cracked tooth.
\end{abstract}

\section{Management of cracked tooth using simvastatin as intra-canal medicament}

\section{Key Clinical Message}

Cracked tooth syndrome is presented as pain associated with biting and sensitivity. Intra-canal medication with simvastatin simulates hard tissue formation at crack line and the tooth was functioning on the followups.

KEY WORDS: Cracked tooth; Intracanal medicament; Simvastatin.

\section{INTRODUCTION}

Cracked tooth syndrome is a common well documented condition that many occur due to morphologic, physical and iatrogenic factors. Epidemiologic data revealed that splits or fractures are the third most common cause of tooth loss, indicating a high clinical significance of this syndrome ${ }^{1}$.

Diagnosis of cracked tooth is challenging, and the treatment has been controversial. Stainless steel bands were often used as a diagnostic tool and a temporary before a full coverage restoration ${ }^{1}$. Root Canal Treatment $(\mathrm{RCT})$, followed by a crown is recommended if the pulp becomes irreversibly inflamed ${ }^{2}$. One study reported successful treatment with a bonded composite restoration after six months, with no differences between restorations with or without cusp coverage ${ }^{3}$. The prognosis of the relevant tooth depends on the extent of the crack and whether the crack has extended through enamel, dentin, pulp and/or the pulp chamber floor. Cracks that extended to the pulpal floor or beyond alveolar bone have been deemed hopeless ${ }^{2}$.

Data involving management of a cracked teeth is rare in the literature, which makes clinical decisions more difficult, and additional information regarding cracked teeth would provide a better perspective on the clinical management and outcome of these teeth. In this case report, we introduce a description for the treatment of a cracked maxillary central incisor using simvastatin as intra-canal medicament.

\section{MATERIALS AND METHODS}

A 23-year-old male dental student was referred to the Department of Endodontics, Faculty of Dentistry, Tanta University. The patient had no significant medical history. His chief complaint was pain associated with 
biting in the maxillary right central incisor. There was a Class III composite restoration in the mesiolabial aspect and superficial longitudinal crack in the labial wall of the crown. Transillumination showed a labial crack line (Figure 1) and cold test caused exacerbation of severe pain that remained after the removal of the stimulus. Gingival tissues were inflamed and there was painful responsive to vertical percussion. However, radiographic examination showed radiolucency in the periapical region and the lamina dura was slightly widened.

The case was diagnosed as irreversible pulp inflammation and the treatment plan involved RCT with management of the cracked crown using simvastatin. Details of the case and the treatment plan were discussed with the patient. He signed an informing consent for using simvastatin with the acknowledge of his understanding that this material will be used as intra-canal medication and it was not previously used for this purpose. The patient agreed and permitted the publication of the case report.

After local infiltration anesthesia of 2\% lidocaine and 1:100,000 epinephrine (Lidocaine, Alex Pharma, Egypt), the tooth was isolated with rubber dam and endodontic access was prepared following the conventional guidelines. A superficial crack was observed from the access preparation in labial wall that extended toward the incisal edge (Figure 2).

The working length was established with apex locator (Root ZX, J. Morita Corp., Tokyo, Japan) at 1 $\mathrm{mm}$ from the radiographic apex. The canal was prepared with ProTaper Universal (Dentsply-maillefer, Ballaigues, Germany) files up to $\mathrm{F} 4$ using $2.5 \%$ sodium hypochlorite $(\mathrm{NaOCl})$ as irrigating solution during instrumentation, and 17\% ethylene diamine tetra acetic acid (EDTA) (META Biomed Co, Korea) as final irrigation to remove the smear layer. Apical patency was kept with a \#10 file and the canal was rinsed with normal saline and dried with paper points. Calcium hydroxide medicament (META Biomed. Co, Korea) was placed into the canal and the coronal cavity was provisionally sealed with a temporary filling material (Cavit G, 3M ESPE, Germany).

The patient was recalled after one week for removal of calcium hydroxide intra-canal medication. He showed pain with filing at the coronal third of the labial wall. In spite of several trials of cleaning, the labial wall of canal preparation appeared dark, sensitive and rough. After removal of calcium hydroxide, simvastatin was use as intra-canal medicament (rest-treatment). Three parts of simvastatin powder (Simvastatin_99\%, HPLC, solid, Abcam) was mixed with one part of distilled water with a sterile metal spatula on a paper pad. When the mixture exhibited a thick creamy consistency, it was immediately carried on the master cone and inserted into the canal. The coronal cavity was then filled with Cavit and occlusal reduction was performed for elimination of occlusal contacts to avoid any overload or possibility of splitting the cracked tooth. The patient was kept at rest-treatment for 3 months. Following that, simvastatin medication was completely removed, and the canal was freshly cleaned as previously mentioned. The canal was then filled with gutta-percha and AH-26 sealer (Dentsply, DeTrey, GmbH, Konstanz, Germany) using lateral condensation technique. A restorative glass ionomer filling (Prima Dental, GL2 2HA, UK) was immediately used to seal the coronal preparation (Figure 3).

\section{RESULTS}

The patient did not report any painful symptom during the rest-treatment and all signs and symptoms had completely disappeared on one-week follow-up recall. On 6-month follow-up, the gingiva appeared normal and the radiograph showed normal periodontal ligaments with normal lamina dura (Figure 4-A). On 12-month follow-up, the tooth was fully functioned without the need for full coverage with clinical and radiographic normal features (Figure 4-B).

\section{DISCUSSION}

Tiny cracks are common and usually do not cause problems. In such cases regular checkups are important to manage such problems in early stage. Various treatment modalities are available for advanced cracks (incomplete fracture). The choice depends on the location, direction and extent of the crack. Cracks may be superficial, affecting the cusp of a tooth or deep to involve the root of the tooth. Some affect only the 
enamel; others may extend to the dentin or the pulp. Before treatment, reduction or elimination of occlusal contacts is essential to avoid an overload of a split tooth ${ }^{2}$.

Tenderness on biting and pain with cold, sweet or hot or a combination of these are common complains of a cracked tooth. These symptoms can be explained by the hydrodynamic theory of pain first described by Feiglin ${ }^{4}$ and substantiated experimentally by Brännström ${ }^{5}$. This theory is based on the concept that rapid movement of dentinal fluid in the dentinal tubules causes pain. This movement stimulates mechanoreceptors in close proximity to the odontoblast cell body, which then activate delta nerve fibers (faster myelinated fibers), resulting in a short sharp pain.

Simvastatin is a new therapeutic material in the field of dentistry and still under dental research. Its structural analogs of HMG-CoA (3-hydroxy-3-mthylglutaryl-coenzyme A) that are considered to be the first-line to control hyperlipidemia and it has been recognized as a safe and low-priced drug with worldwide longtime usage $^{6,7}$. Moreover, statin has multiple functions including anti-inflammation, induction of angiogenesis and improvement of the vascular endothelial cell function. In addition, several statins products have anabolic effects on bone metabolism ${ }^{8}$ and promote mineralization in non-mineralizing osteoblasts through induction of Bone Morphogenic Protein- 2 and osteocalcin ${ }^{9}$. Simvastatin also proved to promote differentiation of osteoplastic cells in mice ${ }^{10}$.

Crack sealed by dentin is considered the proper biological and mechanical management of tooth crack. Simvastatin was used in this clinical report as a intra-canal medicament to seal the tooth crack because previous experimental studies proved that it can stimulate bone ${ }^{11}$ and dentin formation ${ }^{12}$. Painful symptoms disappeared during the rest treatment which proved the therapeutic effects of simvastatin. The exact mechanism or mode of action of simvastatin in the crack seal is not known. However, the anti-inflammatory action of statins may explain the rapid relief of pain after application of the material inside the canal ${ }^{8}$.

The use of simvastatin in the current case is considered as an empirical treatment that was based on experimental studies and further clinical studies should be conducted for investigation of its side effects and mode of action before its approval to be used in endodontics. Regardless the results of this case, the clinicians can apply this approach only when they have scientific evidence.

\section{CONCLUSION}

Fracture is one of the most common causes of tooth loss, therefore, it is important to avoid or eliminate risk factors which contribute to tooth fracture. The key factor is early diagnosis and treatment of the cracks so that they can be halted, or their progression slowed down. Simvastatin allowed a good management for a case suffered from cracked tooth.

\section{AUTHOR CONTRIBUTIONS}

HA: involved in the study design, writing the manuscript, supervision, critical review. MF: involved in conception, materials, writing the manuscript. MS: involved in study design, writing the manuscript. SA: critical review.

\section{CONFLICT OF INTEREST}

The authors deny any conflicts of interest related to this study.

\section{ORCID}

Hatem A. Alhadainy https://orcid.org/0000-0003-0390-418X

Saleem Abdulrab https://orcid.org/0000-0003-0419-2612

\section{REFERENCES}

1. Ehrmann E, Tyas M. Cracked tooth syndrome: Diagnosis, treatment and correlation between symptoms and post-extraction findings.Australian dent $J$. 1990;35(2):105-112. 
2. Ailor JE, Jr. Managing incomplete tooth fractures. JADA2000;131(8):1168-1174.

3. Opdam NJ, Roeters JJ, Loomans BA, Bronkhorst EM. Seven-year clinical evaluation of painful cracked teeth restored with a direct composite restoration. J of Endod 2008;34(7):808-811.

4. Feiglin B. Aspects of dentinal and pulpal pain. Diagnosing Dental Pain. Ann R Aust Coli Dent Surg 1994;12:131-142.

5. Brannstrom M. The hydrodynamic theory of dentinal pain: sensation in preparations, caries, and the dentinal crack syndrome. $J$ of Endod1986;12(10):453-457.

6. Katzung BG, Masters SB, Trevor AJ. Basic and clinical pharmacology: Lange Medical Books/McGrawHill New York, NY, USA; 2004.

7. Mayes PA, Botham KM. Cholesterol synthesis, transport and excretion. In: Murray RK., et al. Harper's Illustrated Biochemistry. Lange Medical Books/McGraw-Hill, 26 ed., New York, Chicago, San Francisco 2003; pages 219-227.

8. Okamoto Y, Sonoyama W, Ono M, Akiyama K, Fujisawa T, Oshima M, et al. Simvastatin induces the odontogenic differentiation of human dental pulp stem cells in vitro and in vivo. J of Endod 2009;35(3):367372.

9. Seto H, Ohba H, Tokunaga K, Hama H, Horibe M, Nagata T. Topical administration of simvastatin recovers alveolar bone loss in rats. $J$ of periodon research . 2008;43(3):261-267.

10. Kamada A, Ikeo T, Tamura I, Goda S, Kawamoto A, Okazaki J, et al. Statin promotes mineralization potential in MC3T3-E1 nonmineralizing subclone. J of Oral Tissue Engineering . 2006;3(3):169-174.

11. Min K-S, Lee Y-M, Hong S-O, Kim E-C. Simvastatin promotes odontoblastic differentiation and expression of angiogenic factors via heme oxygenase-1 in primary cultured human dental pulp cells. $J$ of endod . 2010;36(3):447-452.

12. Aminabadi NA, Maljaei E, Erfanparast L, Aghbali AA, Hamishehkar H, Najafpour E. Simvastatin versus calcium hydroxide direct pulp capping of human primary molars: a randomized clinical trial. J of Dent Res, Dent Clin, Dent Prosp . 2013;7(1):8.

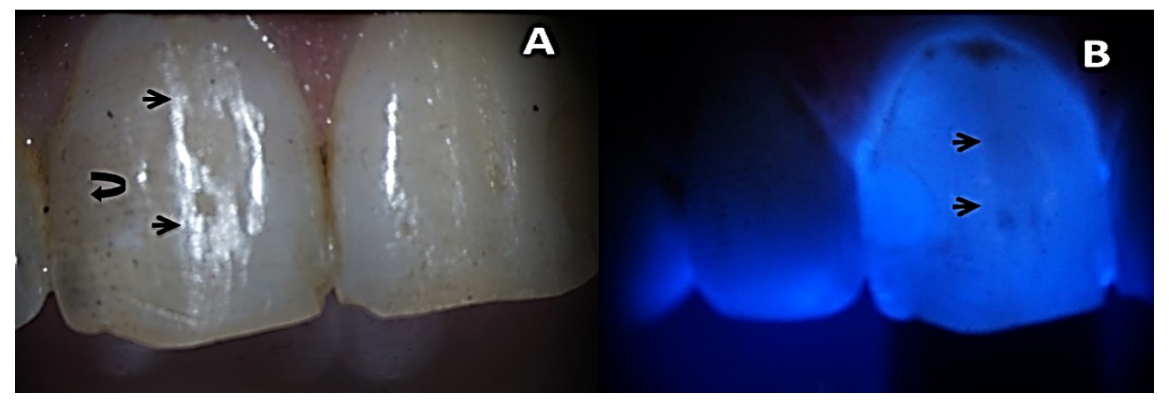

Figure 1: A) Clinical image; small arrows show crack line, curved arrow shows old resin filled restoration. B) Transillumination confirms crack line (arrow). 


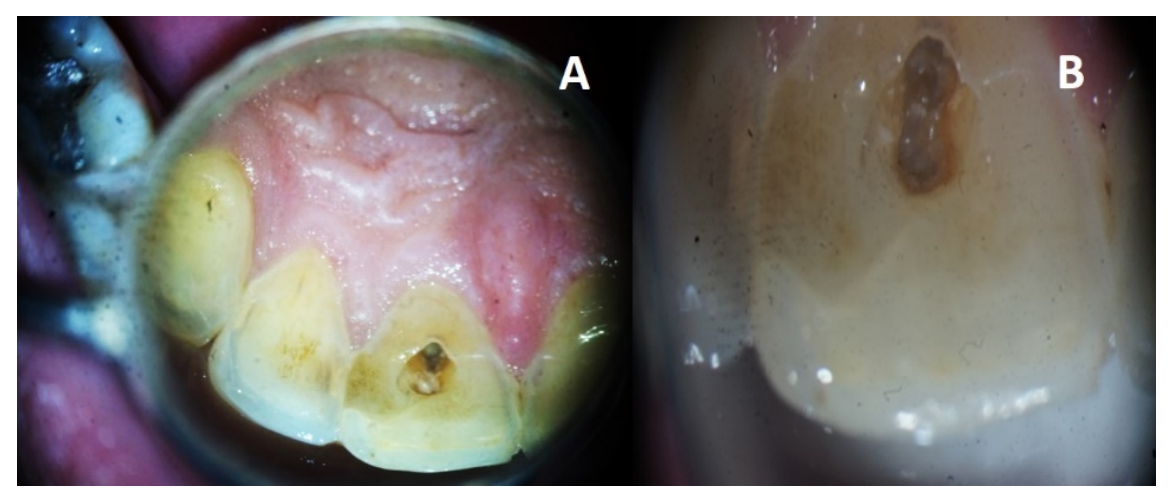

Figure 2: A) Access cavity with dark, and contaminated labial wall. B) Old composite filling (white arrow) and the crack line appears form the preparation on the labial wall (black small arrow).

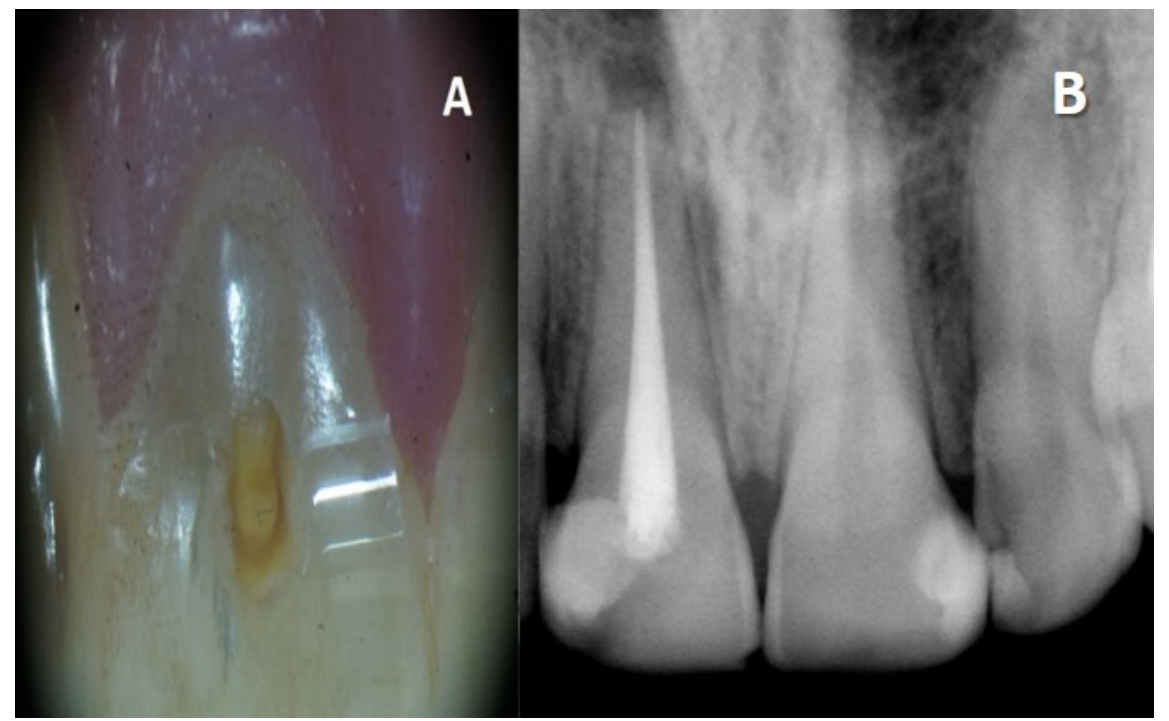

Figure 3: A) Access cavity after removal of simvastatin. B) post-operative radiograph. 


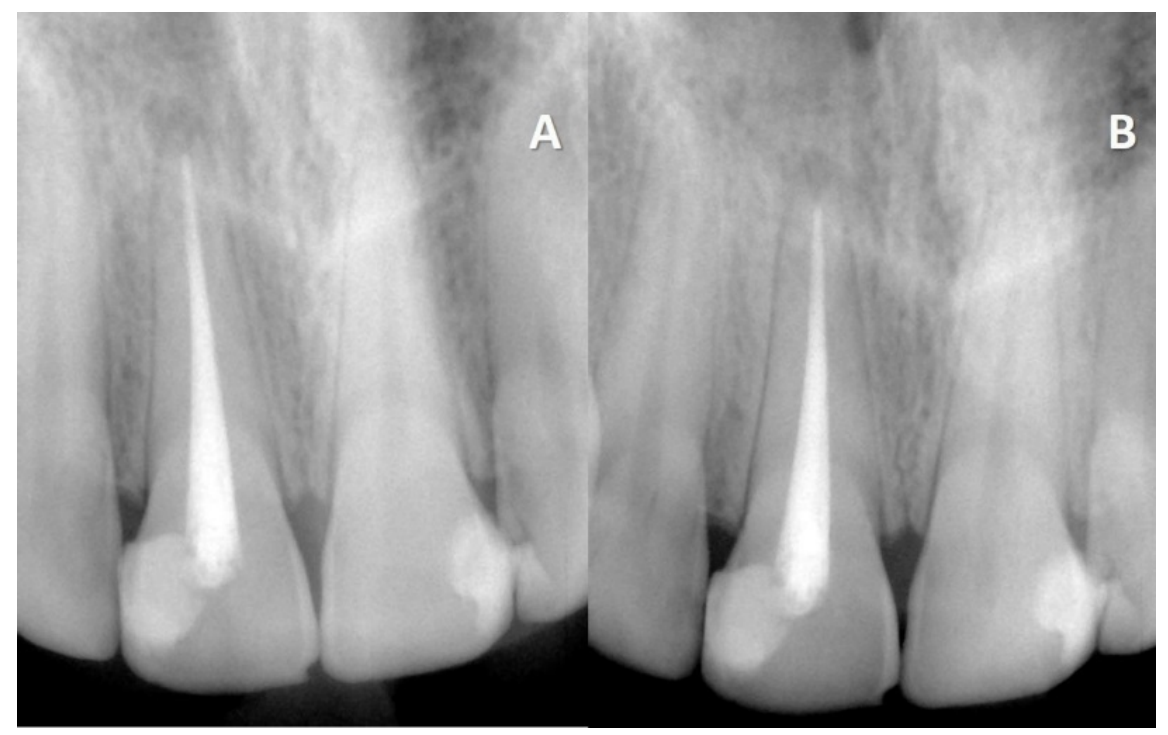

Figure 4: Follow up Radiographs A) 6- month follow up B) 12-month follow up shows complete healing of the apical lesion 